\title{
An open-label, multicentre pilot study of bosentan in pulmonary arterial hypertension related to congenital heart disease
}

\author{
Reda Ibrahim $M D^{1}$, John $T$ Granton $M D^{2}$, Sanjay Mehta $M D^{3}$
}

R Ibrahim, JT Granton, S Mehta. An open-label, multicentre pilot study of bosentan in pulmonary arterial hypertension related to congenital heart disease. Can Respir J 2006;13(8):415-420.

BACKGROUND: Bosentan has been shown to be a safe and efficacious treatment for idiopathic pulmonary arterial hypertension (PAH) and $\mathrm{PAH}$ associated with connective tissue disease. However, there are limited studies examining the benefits of bosentan in PAH associated with congenital heart disease (CHD).

OBJECTIVE: The aim of the present pilot study was to explore the safety and efficacy of bosentan in patients with PAH associated with CHD.

PATIENTS AND METHODS: In the present study, 11 patients with $\mathrm{PAH}$ associated with $\mathrm{CHD}$ were enrolled to receive bosentan for a minimum of 16 weeks ( $62.5 \mathrm{mg}$ twice a day for four weeks; thereafter $125 \mathrm{mg}$ twice a day). Safety was assessed by monitoring adverse events, oxygen saturation, systemic blood pressure, pulse, complete blood count and liver function tests. Efficacy was assessed by the World Health Organization functional class, 6 min walk test (6-MWT), modified Borg dyspnea index, echocardiography and the 36-item short form health survey.

RESULTS: Ten patients completed the 16-week treatment period (one patient withdrew). Bosentan was not associated with a deterioration in resting oxygen saturation $(83.0 \pm 4.6 \%$ at week 16 versus $81.9 \pm 6.1 \%$ at baseline; $\mathrm{P}=0.402$ ), or a deterioration in post-6-MWT oxygen saturation $(70.1 \pm 10.9 \%$ at week 16 versus $68.7 \pm 15.1 \%$ at baseline; $\mathrm{P}=0.747)$. Two patients experienced three serious adverse events. The distance walked in $6 \mathrm{~min}$ improved significantly by $28 \mathrm{~m}$ $(\mathrm{P}=0.005)$ at week 16 compared with baseline, and the modified Borg dyspnea index also improved at week 16 compared with baseline $(\mathrm{P}=0.050)$. The World Health Organization functional class improved from class III to class II for five of 10 patients (50\%). Patients' self-rated quality of life (36-item short form health survey) demonstrated a nonsignificant improvement in each of the eight domains. Obtaining reliable echocardiographic measurements was difficult. Most echocardiographic parameters were only measurable on few patients, and none were measured on all patients, questioning the usefulness of echocardiography as a measuring tool for patients with complex CHD.

CONCLUSION: Bosentan was not associated with worsening of resting oxygen saturation or exercise systemic oxygen saturation, suggesting its potential as a safe treatment option for patients with PAH associated with CHD. Improved 6-MWT and the modified Borg dyspnea index also suggested the possibility of bosentan as an efficacious treatment option for these patients. The results of the present study provide evidence for the need and feasibility of a large randomized, placebo-controlled clinical trial.

Key Words: Congenital heart disease; Endothelin; Hypoxia; Pulmonary hypertension

\author{
Essai pilote, multicentrique de bosentan, mené \\ non à l'insu dans le contexte de l'hypertension \\ artérielle pulmonaire liée à une cardiopathie \\ congénitale
}

CONTEXTE : Le bosentan s'est révélé un traitement sûr et efficace de l'hypertension artérielle pulmonaire (HAP) idiopathique et de l'HAP associée à une maladie du tissu conjonctif. Toutefois, il existe peu d'études sur les bienfaits du bosentan dans le traitement de l'HAP liée à une cardiopathie congénitale (CC).

BUT : La présente étude pilote avait pour but d'évaluer l'innocuité et l'efficacité du bosentan chez des patients atteints d'HAP liée à une CC. PATIENTS ET MÉTHODE : Onze patients atteints d'HAP liée à une $\mathrm{CC}$ ont participé à l'étude et ont reçu du bosentan pendant au moins 16 semaines $(62,5 \mathrm{mg}, 2$ fois par jour [f.p.j.], pendant 4 semaines; puis 125 mg, 2 f.p.j.). L'innocuité a été évaluée d'après la surveillance des effets indésirables, la saturation en oxygène, la pression artérielle générale, le pouls, un hémogramme et des épreuves fonctionnelles hépatiques. L'efficacité, de son côté, a été évaluée d'après les classes fonctionnelles selon l'Organisation mondiale de la santé (OMS), une épreuve de marche de six minutes, l'index modifié de dyspnée de Borg, une échocardiographie et le questionnaire abrégé sur la santé en 36 points.

RÉSULTATS : Dix patients ont terminé le traitement d'une durée de 16 semaines (un patient s'est retiré). Le bosentan n'a pas été associé à une diminution de la saturation en oxygène au repos $(83,0 \pm 4,6 \%$ à la $16^{\mathrm{e}}$ sem. contre [c.] 81,9 $\pm 6,1 \%$ au départ; $\mathrm{P}=0,402$ ) ou après la marche de six minutes $\left(70,1 \pm 10,9 \%\right.$ à la $16^{\mathrm{e}}$ sem. c. $68,7 \pm 15,1 \%$ au départ; $\mathrm{P}=0,747)$. Deux patients ont éprouvé trois effets indésirables graves. Il y a eu une augmentation significative de $28 \mathrm{~m}(\mathrm{P}=0,005)$ de la distance de marche au bout de six minutes entre le début et la fin de l'étude ainsi que de l'index modifié de dyspnée de Borg $(\mathrm{P}=0,050)$. Dans cinq cas sur dix (50\%), la classe fonctionnelle selon l'OMS est passée de III à II. L'autoévaluation de la qualité de vie (questionnaire abrégé en 36 points) par les patients a révélé une amélioration peu importante des indicateurs dans chacun des huit domaines. L'obtention de mesures fiables à l'échocardiographie s'est révélée ardue. La plupart des paramètres échocardiographiques n'étaient mesurables que chez un petit nombre de patients, et aucun n'a pu être mesuré chez tous les patients, ce qui remet en question la pertinence de l'examen comme instrument de mesure chez les patients porteurs d'une CC complexe.

CONCLUSIONS : Le bosentan n'a pas été associé à une diminution de la saturation en oxygène au repos ou à l'effort, ce qui pourrait en faire un traitement sûr chez les patients atteints d'HAP liée à une CC. Par ailleurs, l'amélioration de la longueur de marche et de l'index de Borg pourrait faire du bosentan un traitement efficace chez ces mêmes patients. Les résultats de la présente étude donnent matière à la conduite d'un essai clinique comparatif contre placebo, mené avec hasardisation, à grande échelle.

\footnotetext{
${ }^{1}$ Montreal Heart Institute, University of Montreal, Montreal, Quebec; ${ }^{2}$ Toronto General Hospital, University of Toronto, Toronto; ${ }^{3}$ The Centre for Critical Illness Research, Lawson Health Research Institute, London Health Sciences Centre, University of Western Ontario, London, Ontario Correspondence and reprints: Dr Reda Ibrahim, Montreal Heart Institute, University of Montreal, 5000 East Belanger Street, Montreal,

Quebec H1T 1C8. Telephone 514-376-3330, fax 514-593-2158, e-mail reda.ibrahim@icm-mhi.org
} 
Putong monary arterial hypertension (PAH) is a recognized complication of numerous congenital heart diseases (CHDs). Most originate from an intra- or extracardiac congenital heart defect with systemic to pulmonary (left-to-right) shunt, such as atrial septal defect, ventricular septal defect and/or patent ductus arteriosus. With exposure to protracted high pulmonary arterial blood flow, some of these patients develop an elevation of pulmonary arterial pressure to the systemic level and an irreversible increase of the pulmonary vascular resistance leading to reversed (right-to-left) or bidirectional shunting. This phenomenon is accompanied by hypoxemia and is identified as Eisenmenger syndrome (ES) (1). Unlike idiopathic PAH (IPAH) or other secondary forms of PAH, the prognosis of patients with ES is better and the time from diagnosis to death is longer (2). Despite this, the quality of life in patients with ES is usually significantly impaired $(3,4)$.

Therapeutic options for patients with PAH are limited. Current medical management includes oxygen therapy, anticoagulant therapy, transplantation and vasodilators including calcium channel blockers, prostacyclins and, more recently, sildenafil and endothelin (ET) receptor antagonists. There is less information regarding the efficacy of these agents in CHD patients. Calcium channel blockers have shown limited results or have worsened patients' conditions (5). Prostacyclin therapy has proven to be somewhat more promising. Rosenzweig et al (6) have shown that chronic intravenous infusion of epoprostenol leads to an improvement in hemodynamics and exercise capacity, and reduces the need for transplant after one year of therapy. A second study of prostacyclin therapy in patients with $\mathrm{PAH}$ associated with CHD also showed improvements in hemodynamics (7). However, treatment with epoprostenol requires continuous intravenous infusion through a central venous catheter with a portable pump and individualized dosing regimen, and is associated with significant complications and side effects. Transplantation remains an option in patients with advanced refractory disease. Although some patients are eligible to receive isolated lung transplantation, many patients with more complex diseases require heart-lung transplantation. In general, the longterm results of transplantation are limited due to rejection of the transplant and bronchiolitis obliterans. Consequently, alternative medical therapies for treating these patients, allowing them to avoid more complex medical or surgical therapies, are needed.

Increasing evidence suggests that ET-1 has a pathogenic role in PAH. It is hypothesized to be involved in the development of CHD-associated PAH because high levels of ET have been reported in patients with CHD and ES (8-10). A decrease in ET levels has also been associated with surgical correction of septal defects (11).

Bosentan is an orally administered, dual ET receptor antagonist. Bosentan has been shown to be efficacious in patients with either IPAH or PAH associated with connective tissue diseases with improvements in pulmonary hemodynamics, exercise capacity, modified Borg dyspnea index and time to clinical worsening $(12,13)$. There is emerging evidence from several small studies demonstrating that these benefits are also evident in patients with PAH associated with CHD (14-17). The efficacy and safety of bosentan with CHD has been examined in four separate nonrandomized studies (14-17) and was found to be associated with significant improvements in the 6 min walk test (6-MWT) (15-17), the World Health Organization (WHO) functional status $(14,16,17)$, modified Borg dyspnea index (16) and oxygen saturation (14-17).

\section{STUDY RATIONALE AND OBJECTIVES}

The main safety question addressed in the present pilot study relates to the possibility of systemic hypotension with resultant worsening of the right-to-left shunting. The increase in pulmonary to systemic blood flow through the cardiac shunt may in turn produce more hypoxemia and deterioration in the patient's exercise tolerance or symptoms. The present study was designed to evaluate prospectively, and noninvasively, the effect of bosentan on resting and exercise systemic oxygen saturation, blood pressure and patient symptoms, as well as to provide further efficacy data for chronic oral bosentan therapy in patients with $\mathrm{PAH}$ associated with $\mathrm{CHD}$.

\section{Patient population}

\section{PATIENTS AND METHODS}

The study population consisted of adult patients with $\mathrm{PAH}$ associated with CHD (intra- or extracardiac heart defect with right-to-left or bidirectional shunt). All patients had the WHO functional class III limitations despite optimal medical therapy. Other entry criteria included a baseline 6-MWT distance of $150 \mathrm{~m}$ to $450 \mathrm{~m}$, a stable condition for at least three months before screening and a resting oxygen saturation of $70 \%$ to $90 \%$ while breathing room air.

Patients were excluded if they had left ventricular systolic dysfunction (ejection fraction less than 40\%), coronary arterial disease (CAD), restrictive lung disease (total lung capacity less than $70 \%$ predicted) or obstructive lung disease (forced expiratory volume in the first second less than $70 \%$, with forced expiratory volume in the first second/forced vital capacity less than $60 \%$ ), recent use (within the past three months) of epoprostenol or prostacyclin analogues (excluding short-term use for acute vasoreactivity testing), aspartate aminotransferase and/or alanine aminotransferase values greater than three times the upper limit of normal, hemoglobin or hematocrit levels greater than 30\% below normal range, systolic blood pressure less than $90 \mathrm{mmHg}$ and renal impairment (creatinine greater than $120 \mu \mathrm{mol} / \mathrm{L}$ ).

\section{Design}

The present study was an open-label, multicentre, prospective study, consisting of a screening period (maximum two weeks), a 16-week treatment period (period 1) and a variable follow-up treatment period (period 2). Patients progressed uninterrupted from period 1 to period 2 and continued until the last patient enrolled in the study completed period 1. Approval from each participating centre's ethics committee was secured before the commencement of study enrollment. Patients received bosentan orally, starting at $62.5 \mathrm{mg}$ twice a day for four weeks and, if it was well tolerated, the dose was increased to $125 \mathrm{mg}$ twice a day for the remainder of the study. After completion of the study, patients were invited to participate in a follow-up study designed to collect long-term safety data on the use of bosentan therapy in this patient population.

The dose of bosentan could be reduced to one-half the dose, or temporarily interrupted at any time, for reasons of safety or tolerability. In the case of dose reduction or temporary interruption of bosentan, treatment could be reinstituted at the target dose as soon as the reason for the dose reduction or temporary interruption was no longer applicable.

\section{Safety end points}

The primary safety end point was a change in oxygen saturation, at rest and post-6-MWT, from baseline to week 16. Oxygen saturation was measured indirectly using an automatic pulse oxymeter. The 
same oxymeter and reader was used throughout the study at each site (Nellcor N-20PA [Nellcor Inc, USA] used at two sites and Nellcor $\mathrm{N}-30$ was used at one site). Measurements at rest were taken from the finger with the patient in a seated position after having rested for 5 min.

Other safety assessments included adverse clinical events (including serious adverse events), blood pressure, pulse, body weight, physical examination, laboratory analysis (complete blood count, liver function tests and blood chemistry) and standard 12-lead electrocardiogram. Patients were assessed monthly for the first four months of treatment, and every three months thereafter until the end of study, with the exception of laboratory analyses, which were performed on a monthly basis throughout the study.

\section{Efficacy end points}

Efficacy was measured by the change in exercise capacity from baseline to week 16 as assessed by the 6-MWT. The 6-MWT is a standard end point widely used to measure efficacy in PAH drug trials $(12,13,15-17)$. Other efficacy measures included change from baseline to week 16 in the WHO functional class (18), the modified Borg dyspnea index (19), the 36-item short form health survey (SF-36) (20) and echocardiographic parameters. The 6-MWT and the modified Borg dyspnea index were administered according to the American Thoracic Society guidelines (21). The SF-36 is a valid and reliable general health quality of life scale consisting of 36 questions that fall into eight health domains (20). It is the most widely used quality of life scale in $\mathrm{PAH}$, although a PAH disease-specific quality of life scale is currently under development. Echocardiography was chosen to measure efficacy parameters because it is a noninvasive procedure and reflects current standard practices for CHD patients with PAH. All echocardiography procedures were conducted on instruments capable of two-dimensional, pulsed wave, colour and continuous wave Doppler evaluations. Echocardiography procedures were conducted at the study centres by individuals with a special interest in PAH and then sent to a central reviewer experienced in reading echocardiography results in this patient population, who reviewed all echocardiography procedures for the present study and completed all echocardiography study assessment forms. Efficacy measures were assessed at baseline, week 4, week 16 and end of study with the exception being SF-36 and Doppler echocardiography, which were performed at baseline and week 16 only.

\section{Statistical analysis}

The data were retained and analyzed by the sponsor of the study, Actelion Pharmaceuticals Canada. All authors had full access to the data and had complete independence during the preparation of the manuscript. A priori, a convenience sample size of 10 was determined to be a sufficient number of patients to examine the potential for desaturation during bosentan treatment in the present study, and to determine the feasibility of administering bosentan therapy to this unique patient population in an outpatient setting. The present study also aimed to examine changes in the distance travelled in the 6-MWT, modified Borg dyspnea index, the WHO functional status and echocardiography parameters. Statistical analysis was completed using a safety set $(n=10)$. If the week 16 value of any key safety or efficacy variable (oxygen saturation, 6-MWT, modified Borg dyspnea index and echocardiography) was missing, the patient was excluded from the analysis.

Safety variables: The change from baseline to week 16 for resting oxygen saturation, as well as the mean, standard deviation and statistical significance (meant only for exploratory purposes) were calculated. The baseline and week 16 values for blood

\begin{tabular}{llllr}
$\begin{array}{l}\text { TABLE 1 } \\
\text { Baseline patient demographics and congenital heart } \\
\text { defect diagnosis }\end{array}$ & & & \\
\hline Patients & $\begin{array}{c}\text { Age } \\
\text { (years) }\end{array}$ & Sex & $\begin{array}{l}\text { Congenital heart } \\
\text { defect diagnosis }\end{array}$ & $\begin{array}{c}\text { Years since } \\
\text { PAH diagnosis }\end{array}$ \\
\hline 1 & 19 & Male & Simple VSD & 8.8 \\
2 & 36 & Male & Simple VSD & 16.9 \\
3 & 43 & Female & Simple VSD & 13.9 \\
4 & 22 & Female & ASD + tricuspid and & 2.2 \\
5 & & & pulmonary atresia* & \\
6 & 28 & Male & PDA + truncus arteriosus & 22.3 \\
7 & 31 & Female & Complete AVSD & 5.1 \\
8 & 25 & Female & Complete AVSD & 16.1 \\
9 & 26 & Female & Tetralogy of Fallot* & 6.6 \\
10 & 55 & Female & VSD + truncus arteriosus & 44.9 \\
\hline
\end{tabular}

Mean \pm SD $31.9 \pm 10.7$ $14.4 \pm 12.4$

*Eisenmenger secondary to surgical left-to-right shunts (Blalock and Waterston shunt). ASD Atrial septal defect; AVSD Atrioventricular septal defect; PAH Pulmonary arterial hypertension; PDA Patent ductus arteriosus; VSD Ventricular septal defect

pressure, pulse rate and weight were also tabulated and the frequency, intensity, relationship and outcome of serious adverse events were summarized.

Efficacy variables: The change from baseline to week 16 for the 6-MWT, the modified Borg dyspnea index, SF-36 quality of life scale and the echocardiography variables were calculated, using the paired $t$ test (for normally distributed data) and the paired signed rank test. The baseline value for the 6-MWT and the modified Borg dyspnea index was the average of the screening and baseline values. These two values were averaged to increase the reliability of the value. If the difference between the screening and baseline value of the 6-MWT was greater than $15 \%$, a third 6-MWT was performed. This third test, in turn, had to be less than 15\% different than the second 6-MWT. Patients with a continued difference of greater than $15 \%$ between the screening and baseline value of the 6-MWT were excluded from the study. Change from baseline to week 16 of the WHO functional class was summarized.

\section{RESULTS}

Ten of 11 patients completed the 16-week study (one patient failed to show up for his week 16 visit and voluntarily withdrew himself from the study stating he no longer wished to make the long trip to the clinic every month). This patient was excluded from all analyses. The baseline demographic and CHD characteristics of the 10 patients are presented in Table 1 . None of the patients were undergoing any other form of vasodilator therapy, one patient was undergoing anticoagulant therapy, six patients were taking digoxin, three were undergoing oxygen therapy (as needed) and four patients were taking diuretics.

\section{Safety}

No significant decreases in resting oxygen saturation were observed from baseline $(81.9 \pm 6.1 \%)$ to week 16 of bosentan treatment $(83.0 \pm 4.6 \%)(\mathrm{P}=0.402)$ (Table 2$)$. Post-6-MWT oxygen saturation also did not significantly change from baseline $(68.7 \pm 15.1 \%)$ to week $16(70.1 \pm 10.9 \%)(\mathrm{P}=0.747)$. Six patients experienced an increase in resting oxygen saturation between baseline and week 16 (patients 1, 3, 5, 6, 8 and 9 [Table 2]), one 


\begin{tabular}{|c|c|c|c|c|c|c|}
\hline \multirow[b]{2}{*}{ Patient } & \multicolumn{3}{|c|}{ Resting $\mathrm{SpO}_{2}(\%)$} & \multicolumn{3}{|c|}{ Post-6-MWT SpO $2(\%)$} \\
\hline & Baseline & $\begin{array}{c}\text { Week } \\
16\end{array}$ & $\begin{array}{l}\text { End of } \\
\text { study }\end{array}$ & Baseline & $\begin{array}{c}\text { Week } \\
16\end{array}$ & $\begin{array}{l}\text { End of } \\
\text { study }\end{array}$ \\
\hline 1 & 89 & 90 & 90 & 47 & 81 & 65 \\
\hline 2 & 89 & 86 & 86 & 64 & 73 & 85 \\
\hline 3 & 75 & 79 & 78 & 37 & 43 & 46 \\
\hline 4 & 80 & 75 & 78 & 77 & 70 & 78 \\
\hline 5 & 78 & 80 & 87 & 81 & 77 & 64 \\
\hline 6 & 74 & 80 & 81 & 74 & 68 & 69 \\
\hline 7 & 88 & 88 & 90 & 80 & 81 & 88 \\
\hline 8 & 75 & 82 & 78 & 71 & 74 & 55 \\
\hline 9 & 84 & 86 & 85 & 76 & 65 & 67 \\
\hline 10 & 87 & 84 & 83 & 80 & 69 & 69 \\
\hline
\end{tabular}

Mean \pm SD $81.9 \pm 6.1 \quad 83.0 \pm 4.6 \quad 83.6 \pm 4.7 \quad 68.7 \pm 15.1 \quad 70.1 \pm 10.9 \quad 68.6 \pm 12.8$

patient showed no change (patient 7) and three patients (patients 2, 4 and 10) experienced a decrease. However, none of the decreases were $5 \%$ or greater nor were they associated with symptoms of clinical deterioration. Blood pressure and heart rate remained stable over the course of the study, with no sustained change of more than $5 \%$ for any of the patients. Two patients experienced three serious adverse events during the study. One patient, who was not compliant with her diuretics or with her salt and fluid restriction, was hospitalized for worsening of peripheral edema on two different occasions; both episodes were thought by the investigators to have been exacerbated by bosentan treatment. Both episodes resolved after two days of treatment with intravenous diuretics. The patient completed the initial 16 week study but was taken off the study, during period 2 after the second episode of edema, because she was still noncompliant despite medical advice. The second patient experienced unexplained severe hypoglycemia requiring hospitalization, unrelated to bosentan treatment, which resolved without sequelae. The patient had a history of diabetes, which was thought to be the explanation for the hypoglycemia. The study medication was continued. There were no patients who died or required epoprostenol during the study. Bosentan treatment was not associated with any abnormal laboratory tests, such as reduced hemoglobin or elevated liver enzyme levels.

\section{Efficacy}

During bosentan treatment, nine of 10 patients increased their distance walked between baseline and week 16 in the 6-MWT (Table 3). The average 6-MWT distance increased significantly by $28 \pm 24.5 \mathrm{~m}$ between baseline and week $16 \quad(\mathrm{P}=0.005)$ (Table 3). Consistent with these improvements, eight of 10 patients reported improved breathlessness on the Borg dyspnea index at week 16 compared with baseline, with a mean improvement of 1.5 points on the Borg dyspnea index at week 16 $(\mathrm{P}=0.050)$. At week 16 , five of 10 patients displayed an improvement from WHO functional class III to class II.

There was a nonsignificant improvement in each of the eight health domains of the patients' self-rated quality of life (SF-36) from baseline to week 16 .

The changes from baseline to week 16 in echocardiographic assessments are displayed in Table 4. Due to the complex nature of the CHD in most of these patients, obtaining reliable measures of echocardiographic parameters proved to be very difficult. Several parameters were measurable in only a few patients, and no parameter was measurable in all patients. However, a summary of the echocardiographic results obtained is valuable. At baseline, all patients had echocardiographic evidence of severe PAH causing significant dilation of the right ventricle (RV) and right atrium, with a depressed right ventricular function. This resulted in a distorted left ventricular geometry, as evidenced by reduced left ventricular dimensions and increased end-diastolic and end-systolic interventricular septal eccentricity indices. At week 16, changes from baseline were small but indicated some improvement in right atrial and ventricular dimensions as well as favourable changes in the relative geometry of the left ventricle (LV) and the RV (increases in the LV end-diastolic area and the major diameter/minor diameter end-diastolic ratio of the LV and a decrease in the ratio of RV to LV end-diastolic area). Increases in left ventricular filling pressures and flow across the LV outflow tract were also seen, possibly reflecting an increased flow across the pulmonary bed. No change in ejection fraction was observed while a trend in shunt dimensions was seen, perhaps reflecting a decrease in right-sided chamber dimensions. At baseline, all 10 assessed patients had a bidirectional shunt. No changes in shunt variables were observed at week 16 .

Patients continued on the study until the last patient enrolled completed the week 16 visit. The time of the end of study visit varied from week 17 to week 48 with the average visit occurring at week 35. One patient was withdrawn prematurely from the study during period 2 but did come in for the end of study assessments. This was the patient who experienced a serious adverse event and was hospitalized for worsening of peripheral edema, discussed above. End of study evaluations were performed on 10 of the original 11 patients (Tables 2 and 3). The improvements in efficacy observed at week 16 in 6-MWT, Borg dyspnea index and the WHO functional class were maintained up until the end of study visit. Resting oxygen saturation and post-6-MWT oxygen saturation continued to remain stable up until the end of study (Table 2).

\section{DISCUSSION}

The present study is the first Canadian experience and one of the first prospective clinical evaluations of bosentan in patients with PAH associated with CHD (15-17). In the present pilot study, bosentan was shown to be a safe treatment option for this patient population. Bosentan did not significantly impact resting or exercise oxygen saturation in patients with $\mathrm{CHD}$, despite small decreases in a few patients, suggesting that this drug is not associated with an increase of right-to-left shunting. There was no significant increase in liver enzymes or other laboratory abnormalities. Only one patient experienced a severe adverse event clearly related to bosentan (leg edema) necessitating the discontinuation of the study drug. However, this patient was neither compliant with taking her medications nor her salt and fluid restrictions. None of the patients received intravenous epoprostenol or other vasodilator for clinical deterioration.

Improvements were evident in perceived symptoms of dyspnea in $70 \%$ of the patients (seven of 10), in distance travelled in the 6-MWT (28 m), and in the WHO functional class for $50 \%$ (five of 10) of the patients. Clinical trials have shown that the distance walked in $6 \mathrm{~min}$ correlates with survival rates for patients with PAH (22). The improvement in 6-MWT in the present study is similar to the benefit reported in the recent trials 
TABLE 3

Six minute walk test (6-MWT), modified Borg dyspnea index and World Health Organization (WHO) functional status in each patient at baseline, following 16 weeks of bosentan therapy and at end of study

\begin{tabular}{|c|c|c|c|c|c|c|c|c|c|}
\hline \multirow[b]{2}{*}{ Patient } & \multicolumn{3}{|c|}{ 6-MWT (m) } & \multicolumn{3}{|c|}{ Borg dyspnea index score } & \multicolumn{3}{|c|}{ WHO functional class } \\
\hline & Baseline & Week 16 & End of study & Baseline & Week 16 & End of study & Baseline & Week 16 & End of study \\
\hline 1 & 335.0 & 340 & 354 & 3.0 & 2 & 2 & III & III & II \\
\hline 2 & 336.5 & 383 & 340 & 7.0 & 2 & 2 & III & III & II \\
\hline 3 & 384.5 & 373 & 412 & 5.0 & 3 & 3 & III & II & II \\
\hline 4 & 275.0 & 301 & 300 & 5.5 & 7 & 5 & III & III & III \\
\hline 5 & 410.0 & 420 & 453 & 1.5 & 1 & 2 & III & II & II \\
\hline 6 & 218.5 & 232 & 263 & 8.5 & 9 & 8 & III & III & III \\
\hline 7 & 317.0 & 355 & 330 & 7.0 & 3 & 3 & III & III & III \\
\hline 8 & 231.5 & 260 & 269 & 7.0 & 4 & 3 & III & II & II \\
\hline 9 & 365.0 & 432 & 426 & 3.5 & 3 & 3 & III & II & II \\
\hline 10 & 168.0 & 225 & 234 & 3.5 & 3 & 3 & III & II & II \\
\hline Mean \pm SD & $304.1 \pm 78.5$ & $332.1 \pm 74.7$ & $338.1 \pm 74.1$ & $5.2 \pm 2.2$ & $3.7 \pm 2.5$ & $3.4 \pm 1.8$ & - & - & - \\
\hline
\end{tabular}

of bosentan $125 \mathrm{mg}$ twice a day in patients with other types of $\mathrm{PAH}$, including IPAH and PAH associated with connective tissue disease $(12,13)$. The significant improvement of the 6-MWT also confirmed the data of other small and noncontrolled studies on CHDs with or without ES (14-17). In the largest study, Schulze-Neick et al (17) demonstrated a significant increase in the mean 6-MWT distance from $362 \pm 105 \mathrm{~m}$ to $434 \pm 68 \mathrm{~m}$ $(\mathrm{P}=0.001)$ in 33 patients (only 23 with $\mathrm{ES}$ ). In that study, the baseline transcutaneous oxygen saturation was $86.0 \pm 7 \%$, suggesting that our patients were more compromised. They found no significant change in oxygen saturation at follow-up.

The limited data measurable in this small patient population by echocardiography make it difficult to draw any conclusions. One may speculate on the usefulness of echocardiography in this patient population due to the complex nature of their cardiac disease. Schulze-Neick et al (17) recently reported a significant decrease of the right ventricular systolic pressure measured by echocardiography $(111 \pm 32 \mathrm{mmHg}$ to $106 \pm 22 \mathrm{mmHg}, \mathrm{P}=0.001)$. However, in this cohort of 33 patients, the echocardiographic data were reported for only 18 patients at baseline and 17 patients at follow-up without detailing in which patients the data was collected.

Bosentan is a nonpeptide, competitive, antagonist of both ET type A and B receptors. These receptors have been reported to be upregulated in the pulmonary arteries of the lungs of patients with ES (23). It is currently unclear whether ET is a marker of ES or contributory to the vascular abnormalities in ES. However, the effects of bosentan in patients with IPAH and in this cohort of patients, as well as the known effects of ET on vascular tone and smooth muscle proliferation, suggest that it may have a central role in the pathophysiology and the progression of the disease.

We recognize the limitations of the present study. In such a noncontrolled trial, the placebo effect and bias concerning the degree of subjective clinical improvement cannot be excluded. Thus, in the interpretation of these results, the potential placebo effect associated with 6-MWT, the modified Borg dyspnea index, the SF-36 and the WHO functional status must be considered. In addition, the study cohort was small and nonhomogeneous, limiting the comparison among the patients and the understanding of the mechanism of improvement. Finally, it is important to realize that these results are based on a group of patients who were all WHO functional class III on entry into the study. It is not known whether these results can be applied to patients with

\section{TABLE 4}

Echocardiography: Per cent change from baseline to week 16, safety population

\begin{tabular}{|c|c|c|c|}
\hline $\begin{array}{l}\text { Echocardiography } \\
\text { variable }\end{array}$ & $\mathbf{n}$ & Baseline $(95 \% \mathrm{Cl})$ & $\begin{array}{l}\text { Per cent change at } \\
\text { week } 16(95 \% \mathrm{Cl})\end{array}$ \\
\hline RV ET (ms) & 6 & 257.0 (196 to 317$)$ & $0.3(-16.5$ to 17.0$)$ \\
\hline Max TR jet $(\mathrm{cm} / \mathrm{s})$ & 4 & 459.0 (300.3 to 617.7$)$ & $6.8(-12.3$ to 25.8$)$ \\
\hline Right atrial area $\left(\mathrm{cm}^{2}\right)$ & 7 & $20.4(13.8$ to 27.0$)$ & $-4.4(-18.5$ to 9.7$)$ \\
\hline $\operatorname{RV} \operatorname{EDA}\left(\mathrm{cm}^{2}\right)$ & 7 & $23.8(6.9$ to 40.7$)$ & $-11.0(-24.7$ to 2.6$)$ \\
\hline RV ESA $\left(\mathrm{cm}^{2}\right)$ & 7 & $19.3(2.5$ to 36.0$)$ & $-10.2(-33.0$ to 12.7$)$ \\
\hline LV EDA $\left(\mathrm{cm}^{2}\right)$ & 9 & $32.2(24.1$ to 40.4$)$ & $3.6(-12.6$ to 19.8$)$ \\
\hline $\begin{array}{l}\text { IVC minimum } \\
\text { diameter }(\mathrm{cm})\end{array}$ & 6 & $1.0(0.2$ to 1.8$)$ & $2.3(-39.9$ to 44.4$)$ \\
\hline TVI (LVOT) (cm) & 8 & 19.0 (13.9 to 24.1$)$ & 9.1 (-11.8 to 30.1$)$ \\
\hline$E(\mathrm{~cm} / \mathrm{s})$ & 8 & 75.3 (55.8 to 94.7 ) & $14.7(-3.5$ to 33.0$)$ \\
\hline $\mathrm{A}(\mathrm{cm} / \mathrm{s})$ & 8 & 64.5 (47.9 to 81.1$)$ & $-2.7(-30.1$ to 24.7$)$ \\
\hline Ejection fraction (\%) & 7 & $61.4(57.9$ to 64.9$)$ & $0.0(0.0$ to 0.0$)$ \\
\hline Size of defect $(\mathrm{cm})$ & 7 & $2.5(1.8$ to 3.1$)$ & $-10.7(-21.9$ to 0.6$)$ \\
\hline AcT/RVET & 6 & $0.3(0.2$ to 0.4$)$ & $2.1(-29.4$ to 33.5$)$ \\
\hline RV/LV EDA & 7 & $0.9(0.1$ to 1.8$)$ & $-14.4(-29.9$ to 1.1$)$ \\
\hline D1/D2 end-diastole & 6 & $0.73(0.60$ to 0.86$)$ & $15.4(-17.2$ to 48.1$)$ \\
\hline D1/D2 end-systole & 6 & 0.73 (0.60 to 0.87$)$ & $4.2(-18.8$ to 27.2$)$ \\
\hline Tei index & 4 & $0.96(0.47$ to 1.44$)$ & $17.6(-45.5$ to 80.6$)$ \\
\hline $\begin{array}{l}\text { Doppler-derived } \\
\text { cardiac index } \\
\left(\mathrm{L} / \mathrm{min} / \mathrm{m}^{2}\right)\end{array}$ & 3 & $2.5(2.0$ to 3.1$)$ & $-12.2(-34.0$ to 9.6$)$ \\
\hline RV \% change & 7 & 22.0 (11 to 34$)$ & $-38.8(-202.5$ to 125.0$)$ \\
\hline E/A & 8 & $1.0(1$ to 2$)$ & $46.7(-53.8$ to 147.2$)$ \\
\hline
\end{tabular}

AcT Acceleration time; D1 Major diameter of the left ventricle; D2 Minor diameter of the left ventricle; E/A Ratio of early $(E)$ to late $(A)$ atrial mitral Doppler peak flow velocity; EDA End-diastolic area; ESA End-systolic area; IVC Inferior vena cava; LV Left ventricular; LVOT Left ventricle outflow tract; RV Right ventricular; RVET RV ejection time; TR Tricuspid regurgitation; TVI Time velocity integral

either milder (WHO class I to class II) or more severe disease (WHO class IV).

\section{CONCLUSION}

Bosentan proved to be a safe and well tolerated treatment option in patients with PAH, despite the fact that the majority of these patients had complex CHDs. Bosentan was associated with significant improvements in exercise capacity and symptoms and 
did not cause worsening of right-to-left shunting. The present study demonstrated that bosentan can safely be administered in an outpatient setting. However, given the complexity of the cardiac disease in most of these patients, the use of echocardiography as a measure of disease status was determined to be an unreliable method of surveillance in this cohort. The promising safety and efficacy profile demonstrated in the present open-label pilot study, provides evidence for the need and the feasibility of a large randomized placebo-controlled trial within this patient population.

COMPETING INTEREST STATEMENTS: The present research was funded by Actelion Pharmaceuticals Canada Inc. Dr Sanjay Mehta is a consultant for and has participated in speaker's bureau for Actelion Pharmaceuticals Canada Inc; Encysive Pharmaceuticals, USA; GlaxoSmithKline Inc, Canada; Northern Therapeutics Inc, Canada and Pfizer Inc, Canada. He has received research support from Actelion Pharmaceuticals Canada Inc, Encysive Pharmaceuticals and Pfizer Inc. He has no other financial or proprietary potential conflicts of interest. Dr Reda Ibrahim has been reimbursed by Actelion Pharmaceuticals Canada, the manufacturer of bosentan, for speaking and for running education programs. Dr John Granton has received fees for consulting and speaking as well as research funds from Actelion Pharmaceuticals Canada.

\section{REFERENCES}

1. Wood P. The Eisenmenger syndrome or pulmonary hypertension with reversed central shunt. Br Med J 1958;46:755-62.

2. Granton JT, Rabinovitch M. Pulmonary arterial hypertension in congenital heart disease. Cardiol Clin 2002;20:441-57,vii.

3. Hopkins WE, Ochoa LL, Richardson GW, Trulock EP. Comparison of the hemodynamics and survival of adults with severe primary pulmonary hypertension or Eisenmenger syndrome. J Heart Lung Transplant 1996;15:100-5.

4. Benisty JI, Landzberg MJ. Eisenmenger's Syndrome. Curr Treat Options Cardiovasc Med 1999;1:355-62.

5. Gildein HP, Wildberg A, Mocellin R. [Comparative studies of hemodynamics under prostacyclin and nifedipine in patients with Eisenmenger syndrome]. Z Kardiol 1995;84:55-63

6. Rosenzweig EB, Kerstein D, Barst RJ. Long-term prostacyclin for pulmonary hypertension with associated congenital heart defects. Circulation 1999;99:1858-65.

7. McLaughlin VV, Genthner DE, Panella MM, Hess DM, Rich S. Compassionate use of continuous prostacyclin in the management of secondary pulmonary hypertension: A case series. Ann Intern Med 1999;130:740-3.
8. Adatia I, Haworth SG. Circulating endothelin in children with congenital heart disease. Br Heart J 1993;69:233-6.

9. Bando K, Vijayaraghavan P, Turrentine MW, et al. Dynamic changes of endothelin-1, nitric oxide, and cyclic GMP in patients with congenital heart disease. Circulation 1997;96:346-51.

10. Yoshibayashi M, Nishioka K, Nakao K, et al. Plasma endothelin concentrations in patients with pulmonary hypertension associated with congenital heart defects. Evidence for increased production of endothelin in pulmonary circulation. Circulation 1991;84:2280-5.

11. Ishikawa S, Miyauchi T, Sakai S, et al. Elevated levels of plasma endothelin-1 in young patients with pulmonary hypertension caused by congenital heart disease are decreased after successful surgical repair. J Thorac Cardiovasc Surg 1995;110:271-3.

12. Rubin LJ, Badesch DB, Barst RJ, et al. Bosentan therapy for pulmonary arterial hypertension. N Eng J Med 2002;346:896-903. (Erratum in 2002;346:1258).

13. Channick RN, Simonneau G, Sitbon O, et al. Effects of the dual endothelin-receptor antagonist bosentan in patients with pulmonary hypertension: A randomised placebo-controlled study. Lancet 2001;358:1119-23.

14. Christensen DD, McConnell ME, Book WM, Mahle WT. Initial experience with bosentan therapy in patients with the Eisenmenger syndrome. Am J Cardiol 2004;94:261-3.

15. Gatzoulis MA, Rogers P, Li W, et al. Safety and tolerability of bosentan in adults with Eisenmenger physiology. Int J Cardiol 2005;98:147-51.

16. Apostolopoulou SC, Manginas A, Cokkinos DV, Rammos S. Effect of the oral endothelin antagonist bosentan on the clinical, exercise, and haemodynamic status of patients with pulmonary arterial hypertension related to congenital heart disease. Heart 2005;91:1447-52.

17. Schulze-Neick I, Gilbert N, Ewert R, et al. Adult patients with congenital heart disease and pulmonary arterial hypertension: First open prospective multicenter study of bosentan therapy. Am Heart J 2005;150:716.

18. Simonneau G, Galie N, Rubin LJ, et al. Clinical classification of pulmonary hypertension. J Am Coll Cardiol 2004:43(Suppl 12):5S-12S

19. Borg GA. Psychophysical bases of perceived exertion. Med Sci Sports Exerc 1982;14:377-81.

20. Hays RD, Sherbourne CD, Mazel RM. The RAND 36-Item Health Survey 1.0. Health Econ 1993;2:217-27.

21. American Thoracic Society. ATS statement: Guidelines for the 6-minute walk test. Am J Respir Crit Care Med 2002;166:111-7.

22. Miyamoto S, Nagaya N, Satoh T, et al. Clinical correlates and prognostic significance of six-minute walk test in patients with primary pulmonary hypertension. Comparison with cardiopulmonary exercise testing. Am J Respir Crit Care Med 2000;161:487-92.

23. Berman EB, Barst RJ. Eisenmenger's syndrome: Current management. Prog Cardiovasc Dis 2002;45:129-38. 


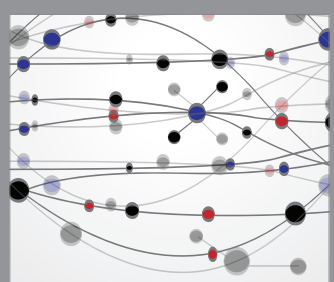

The Scientific World Journal
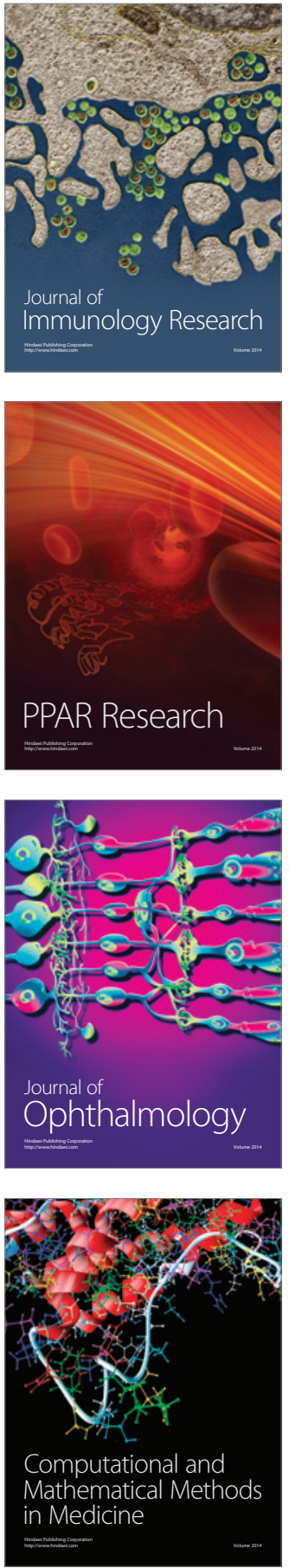

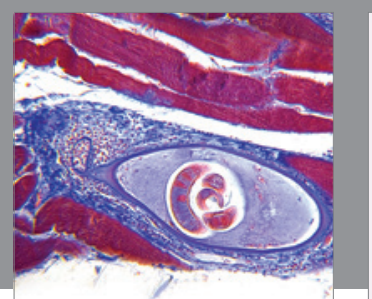

Gastroenterology Research and Practice

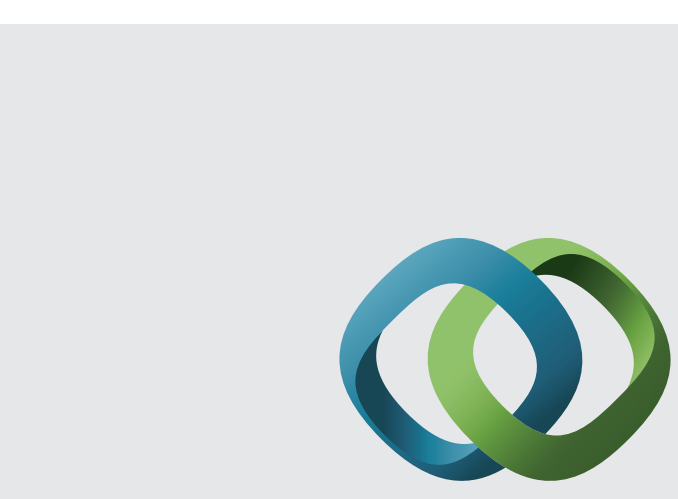

\section{Hindawi}

Submit your manuscripts at

http://www.hindawi.com
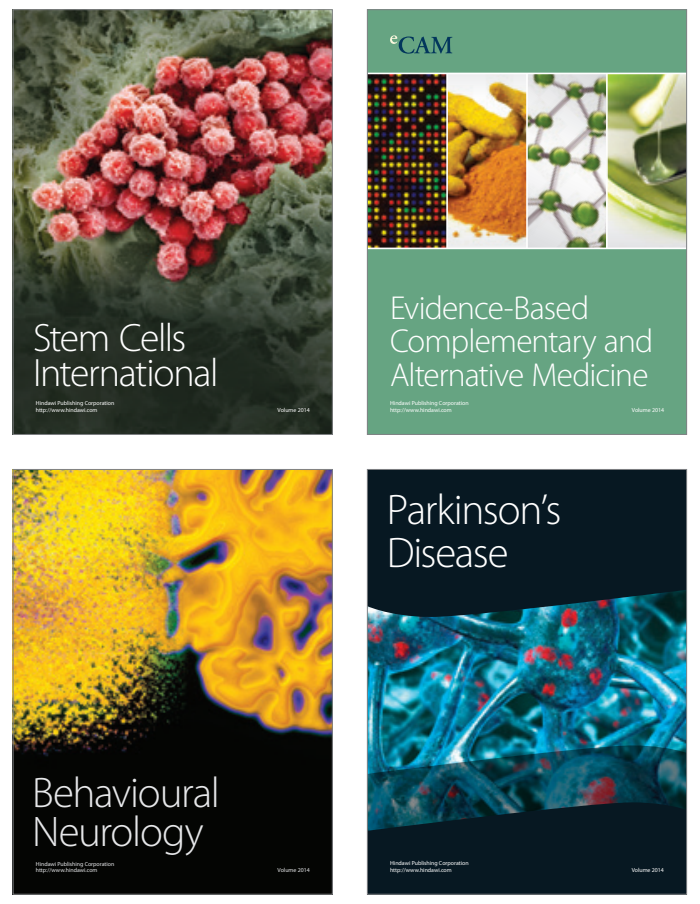
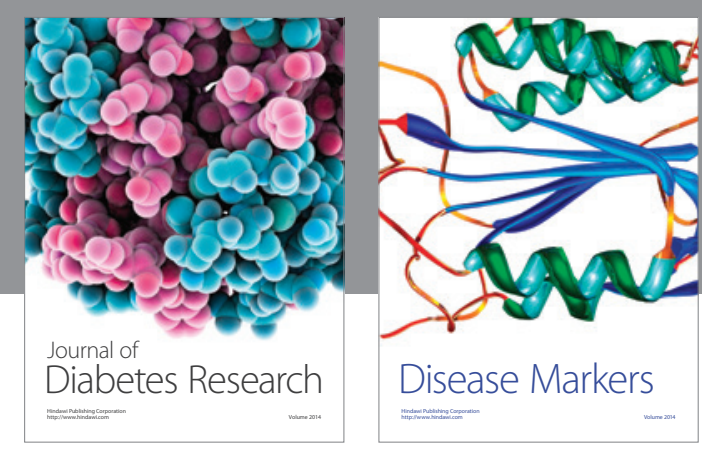

Disease Markers
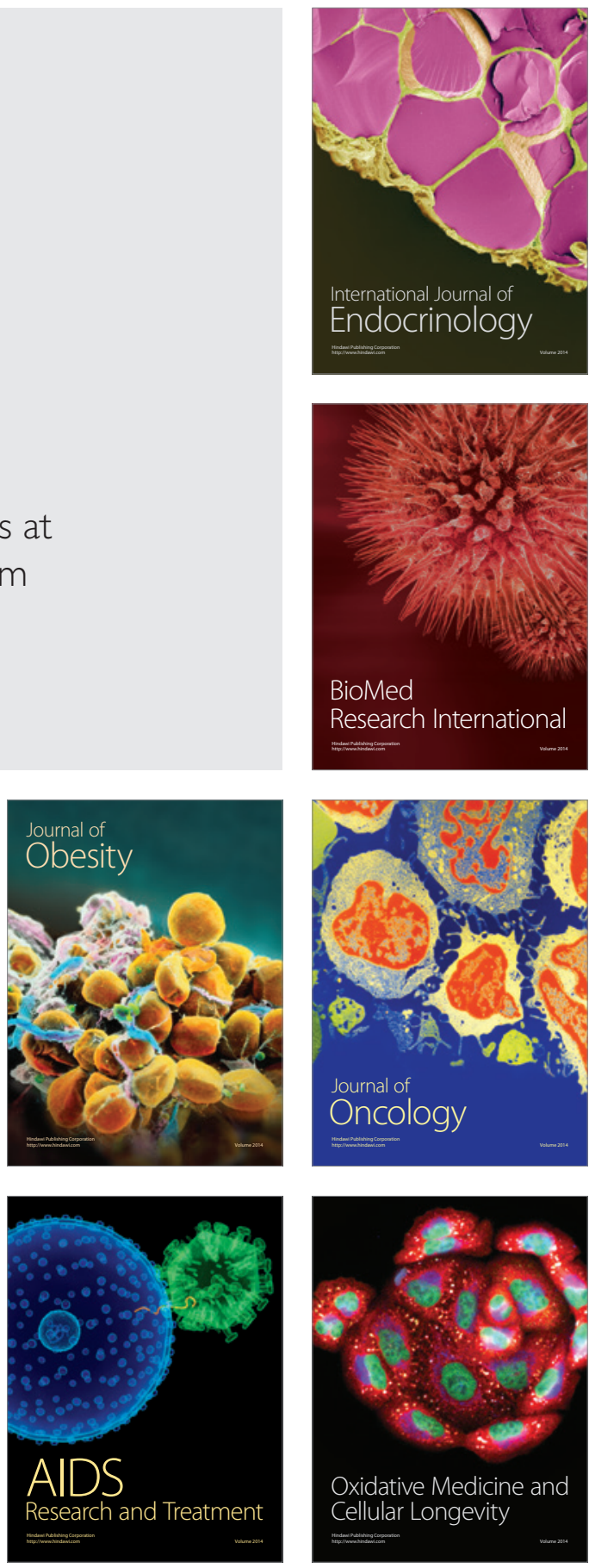